Research Article

\title{
Management of Lateral Epicondylitis: A Narrative Literature Review
}

\author{
Kun-Long $\mathrm{Ma}^{1}$ and Hai-Qiang Wang $\mathbb{D}^{2}$ \\ ${ }^{1}$ Department of Orthopedics, Yongchuan Hospital of Chongqing Medical University, Hua Road, No. 439, Yongchuan, \\ Chongqing 402160, China \\ ${ }^{2}$ Institute of Integrative Medicine, Shaanxi University of Chinese Medicine, Xixian Avenue, Xixian District, Xi'an 712046, \\ Shaanxi Province, China \\ Correspondence should be addressed to Hai-Qiang Wang; drwanghq@163.com
}

Received 1 August 2019; Revised 14 November 2019; Accepted 22 April 2020; Published 5 May 2020

Academic Editor: Giustino Varrassi

Copyright ( $\odot 2020$ Kun-Long Ma and Hai-Qiang Wang. This is an open access article distributed under the Creative Commons Attribution License, which permits unrestricted use, distribution, and reproduction in any medium, provided the original work is properly cited.

\begin{abstract}
Lateral epicondylitis, also termed as "tennis elbow," is the most common cause of elbow pain and dysfunction, mainly resulting from repetitive gripping or wrist extension during various activities. The exact pathogenesis remains largely elusive with putative tendinosis, a symptomatic degenerative process of the local tendon. It is usually diagnosed by clinical examinations. Sometimes, additional imaging is required for a specific differential diagnosis. Although most cases can be self-healing, the optimal treatment strategy for chronic lateral epicondylitis remains controversial. This article presents a landscape of emerging evidence on lateral epicondylitis and focuses on the pathogenesis, diagnosis, and management, shedding light on the understandings and treatment for healthcare professionals.
\end{abstract}

\section{Introduction}

Lateral epicondylitis (LE) was first described in the English literature by Runge in 1873 [1]. It was described as chronic symptomatic degeneration of the forearm common extensor tendon attachment at the humeral ectocondyle. It is one of the most common overuse syndromes in primary medical care. LE affects $1 \%$ to $3 \%$ of the population, mainly those middleaged people without gender difference [2]. LE can produce a great social and economic burden due to lost workdays and can even disable some patients from working for weeks $[3,4]$. Despite advances in the treatment of LE, there is still a lack of established standards. It is generally self-limiting, and most cases require no treatment, with up to $80 \%$ cases recovering within one year [5]. Patients with refractory symptoms may require further conservative or surgical treatments.

\section{Pathogenesis}

The exact etiology of LE has not been well identified. However, it is commonly associated with repetitive microtrauma from excessive gripping or wrist extension, radial deviation, and/or forearm supination $[6,7]$. The extensor carpi radialis brevis (ECRB) is the most frequently affected muscle. The pronator and other extensor carpal muscles are also commonly affected [8]. In addition to the factor of excessive mechanical forces, the unique origin of ECRB in the lateral aspect of the capitellum places the tendon at risk for repeated undersurface abrasion during elbow extension and flexion [9]. LE was originally considered as an inflammatory process, especially in its initial phases. Repetitive microtrauma resulting from overload or overuse can cause collagen fibril rupture and the activation of the innate immune system $[10,11]$. However, histopathological studies have shown that there is absence of inflammatory cells in biopsies of chronic LE $[12,13]$. Accumulating evidence identifies it as tendinosis, a symptomatic degenerative process characterized by an abundance of fibroblasts, vascular hyperplasia, and unstructured collagen. These findings were termed as angiofibroblastic hyperplasia by Nirschl and Alvarado [14]. The mechanical properties of tendons are commonly determined by the 
structure of protein molecular and the composition of the extracellular matrix [15]. Strain upon a tendon normally promotes cross-linkage and collagen deposition [13]. In situations of repetitive stretching, multiple microtears of the tendon potentially cause an irreversible denaturing of matrix proteins and proliferation of fibrous tissue [16]. Over time, these scar tissues are vulnerable to repetitive forces, with subsequent further tears. High-frequency cyclical trauma and immature repair result in more severe tears, with consequent alteration and failure of musculotendinous biomechanics and worsening of symptoms [17].

Emerging evidence indicates a significant link between the strain degree of tendons and the extent of injuries $[18,19]$. Strains less than $4 \%$ generally allow the tendon restore its original length after unloading, but the collagen fibers begin to fail when the strains are more than $4 \%$, and it will be prone to rupture when the strains are over $8 \%$. Kraushaar and Nirschl [13] described four stages of tendinosis, facilitating the recognition of the degenerative process of LE (Table 1). Notwithstanding the main cause is degeneration, additional pathophysiological mechanisms also contribute to the development of tendinosis. LE patients with painful symptoms often involuntarily lead to "underuse" or stress shielding of affected tendons, which subsequently results in structural weakening of the tendon, making it more sensitive to injury [18]. Meanwhile, increasing shear forces promotes fibrocartilaginous formation at tendon enthesis, which contributes to weakening at the tendon-bone junction and initiating development of tendinosis [20].

Histopathological studies have shown defects and necrosis inside the tendon fibers within tendons in patients with chronic LE, which is ascribed to strong association with underuse of the affected limb due to pain-related immobilization [20]. In addition, inadequate tendon angiogenesis and continuous muscle contraction can lead to tendon ischaemia, which further aggravates the development of tendinosis [21].

As for the pain machinery of LE, most studies ascribe the pathogenesis of LE to neurogenic etiology based on several lines of evidence indicating the presence of nerve fibers with reactivity to neuropeptides, including substance $\mathrm{P}(\mathrm{SP})$ and calcitonin gene-related peptide (CGRP) [22-24]. Ljung et al. [22] observed 5 patients with LE and 4 patients with medial epicondylitis (ME) by immunohistochemistry, indicating that the SP/CGRP innervation was present in the pathologic tendon tissues of LE as well as ME patients. Neurokinin-1 receptor immunoreaction was noted as varicose fibers in the form of a single fiber or nerve bundles. Thus, the findings present emerging evidence for a possible neurogenic pathogenesis of LE and ME. Uchio et al. [23] concluded that neuropeptides (SP and CGRP) and cytokines (interleukin$1 \alpha$ (IL- $1 \alpha)$ and tumor growth factor- $\beta$ (TGF- $\beta$ ) ) might be involved in the pathogenesis of LE. However, further studies are needed to clarify the intrinsic relationship between neuropeptides and cytokines. Furthermore, Han et al. [24] studied the mRNA levels of neuropeptides and cytokines in LE with corticosteroid injection treatment. In vivo study found that the expression of SP mRNA was maximally inhibited by corticosteroid triamcinolone acetonide (TAA) at 24 hours but recovered at 72 hours. CGRP mRNA and IL$1 \alpha$ mRNA were inhibited at 24 and 3 hours, respectively. Consequently, the reaction mechanism of the corticosteroid for relieving pain in LE is mainly achieved by inhibiting the expression of neuropeptides and cytokines. Besides, a significant positive correlation between CGRP and IL- $1 \alpha$ was also noted after 72 hours of TAA treatment, implicating the role of neurogenic inflammation in the pathogenesis of LE.

\section{Clinical Evaluation}

Patients often complain of pain or burning around the lateral epicondyle of the humerus, which frequently radiates down the forearm and sometimes extends proximally to the upper arm. This pain is usually triggered or exacerbated by a variety of activities involving wrist extension under resistance, such as grasping objects or twisting towels [25, 26]. The degree of the pain often ranges from mild to severe degrees and from intermittent to persistent, which seriously affects patients' daily life quality. In addition, patients often complain of weakness on gripping and difficulty in lifting [27]. During physical examinations, marked tenderness is usually inspected at the origin of the ECRB in the lateral epicondyle [28]. The pain can be exacerbated with resisted wrist extension, middle finger extension, and forearm supination with the elbow in the extended position. Usually, normal elbow motion can be preserved even in some severe cases [26].

Nirschl and Ashman [29] proposed a classification system and thus separated LE into seven phases based on the level of pain (Table 2). Although there is no complete correlation between histological lesions and clinical features of each phase, their supposed theoretical correlation is helpful to guide the treatment of LE.

\section{Diagnosis}

Most cases of LE can be clinically confirmed by thorough history inquiry and physical examinations. The contents of medical history collection usually include occupation, hand dominance, daily behaviors and habits, duration of symptoms, date of prior episodes, number of recurrences, inducing or aggravating factors, treatment modalities, and tobacco use. The duration of symptoms and number of recurrences are two key important factors to determine the stage of LE [30].

Any test capable of triggering the typical symptoms of LE can be considered as an effective examination modality for diagnosing LE. Resistance of the middle finger extensor can cause elbow pain due to selective recruitment of the ECRB tendon [31]. Resistance of wrist extensors with full elbow extension and pronation can reproduce the pain in mild-tomoderate cases [25]. Special tests are commonly used during the physical examination, such as the chair test, Cozen's test, and Mill's test [32,33]. Chair test requires the patient to lift a chair with the shoulder adducted, elbows extended, and forearms pronated. Pain on the lateral epicondyle indicates lateral epicondylitis. Cozen's test requires the patient seated, 
TABle 1: Pathologic stages of lateral epicondylitis.

\begin{tabular}{lc}
\hline Stage & Degenerative changes of tendinosis \\
\hline I & Peritendinous inflammation with no pathological alterations \\
II & Involving pathological alterations such as tendinosis or angiofibroblastic degeneration \\
III & Involving pathological changes and complete structural failure \\
IV & Involving fibrosis, soft matrix calcification, and hard osseous calcification, in addition to the features of stage II or III \\
\hline
\end{tabular}

TABLE 2: Clinical classification of lateral epicondylitis phases.

\begin{tabular}{|c|c|}
\hline Phase & Description of pain changes of different phases \\
\hline I & Mild pain after activity, usually recovers within 24 hours \\
\hline II & $\begin{array}{c}\text { Mild pain more than } 48 \text { hours after activity, no pain during activity, can be relieved with warm-up exercises, and recovers within } 72 \\
\text { hours }\end{array}$ \\
\hline III & $\begin{array}{c}\text { Mild pain before and during activity, no significant negative impact on the activities, and can be partially relieved with warm-up } \\
\text { exercises }\end{array}$ \\
\hline IV & Mild pain accompanies the activities of daily living and has negative impact on the performance of activities \\
\hline $\mathrm{V}$ & $\begin{array}{l}\text { Harmful pain unrelated to activities, great negative impact on the performance of activities but does not prevent the activities of } \\
\text { daily life. Need complete rest to control the pain }\end{array}$ \\
\hline VI & Persistent pain despite \\
\hline VII & Consistent pain at rest, aggravated after activities, and disturbed sleep \\
\hline
\end{tabular}

Notes: the pain in phases I and II is usually self-limiting with due care and protection; the pain in phases III and IV usually needs some nonoperative treatments; and the pain in phases V-VII is more likely to require operative treatment.

with the elbow extended, forearm maximal pronation, the wrist radially abducted, and the hand in a fist. Then, the examiner moves the wrist to dorsal flexion and moves the wrist towards palmar flexion. Mill's test requires the patient seated, elbow extended, and forearm pronated. Then, the examiner moves the wrist passively in palmar flexion and hereby stretching the extensors.

Besides, grip weakness is also been considered as an effective test, with $83 \%$ accuracy in determining LE [27]. However, when clinical symptoms cannot be well defined based on physical examination and history, diagnostic imaging may be needed. Although negative findings are usually noted for radiographs, useful information can be obtained in terms of revealing bone diseases, such as arthropathy, osteochondral defects, loose bodies, and calcifications of ECRB origin [26]. Although CT is more sensitive than MRI in identifying tears of capsule, it is rarely used in the diagnosis of LE because of ionizing radiation [34].

Ultrasound is considered as an efficient, noninvasive, and relatively cost-effective imaging method for LE [35]. There are a variety of findings on ultrasound for identifying degenerative changes of the tendons attached to the region of the lateral epicondyle, which includes bone irregularities, calcific deposit, thickening, thinning, and tears of affected tendons or capsule [36]. Moreover, neovascularization can also be detected by ultrasound. If none of these findings is detected, LE can be probably ruled out [37].

In comparison with ultrasound, MRI can provide a better view of the complete anatomical structures of the lateral epicondyle [38]. Primary findings of elbow MRI include signs of abnormal thickening tendon and capsule and increased signal intensity within the common extensor origin. MRI can also identify partial or full-thickness tears of the ECRB, which can influence the need for surgical management and be helpful during preoperative planning
[39]. In comparison with ultrasound, however, MRI is of limited diagnostic value in determining the overall extent and size of tendon tearing [40]. MRI is usually considered for the possible intra-articular pathology. It is not recommended routinely owing to its cost and the inconsistence of clinical symptoms with imaging findings [41].

LE is the leading cause of elbow pain; however, similar pain caused by other diseases should be carefully identified to avoid misdiagnosis. These potential diseases mainly include cervical radiculopathy, frozen shoulder, radial tunnel syndrome, lateral plica syndrome of the elbow, posterolateral elbow instability, and inflammatory edema of the elbow muscle. Other causes of pain include low-grade infection or other inflammatory diseases, such as rheumatoid arthritis.

\section{Treatment}

A variety of treatment options have been recommended for LE. Unfortunately, there are still no universally accepted therapeutic modalities. However, the treatment of LE usually has five therapeutic goals: controlling elbow pain, preserving movement of the affected limb, improving grip strength and endurance, restoring normal function of the affected limb, and preventing further deterioration [26]. Nonoperative treatment remains the priority and mainstay for most patients with LE. Surgical intervention is available for recalcitrant cases.

5.1. Nonoperative Treatment. Nonoperative treatment can significantly resolve the symptomatic LE in $90 \%$ of cases $[42,43]$. Nonoperative care usually includes activity modification, physiotherapy, nonsteroidal anti-inflammatory medications, bracing, extracorporeal shock-wave therapy, and acupuncture. With a promising result, biotherapy 
method has been very popular in recent years, including autologous blood injections (ABI) and platelet-rich plasma injections (PRP).

5.1.1. Activity Modification. Modification of activity and avoidance of overwork are essential components for any treatment protocol. Turning the palm up while lifting and avoiding palm-down exercises can transfer the force away from the lateral epicondyle to the medial epicondyle and help alleviate lateral elbow pain. Besides, LE patients should be advised to correct adverse living habits and stay away from some inciting activities. The principle of RICE (rest, ice, compression, and elevation) can be helpful to relieve pain at the initial stage.

5.1.2. Physiotherapy. Various physiotherapy modalities are recommended for the treatment of LE. Traditional treatment options include electrotherapeutic and nonelectrotherapeutic modalities, aiming for improving function and reducing pain by stretching and strengthening the affected wrist extensors [44-48]. Recently, eccentric exercise (EE) has gradually been a first-line conservative treatment for LE. EE is executed via stretching the musculotendinous unit with an applied load [49]. Clinical trials have demonstrated that the EE has superior efficacy in the treatment of LE, in comparison with therapeutic ultrasound, [50] bracing, [51], and a combination of multiple interventions [52]. Although the EE has a promising outcome, the exact mechanisms underlying $\mathrm{EE}$ in treating $\mathrm{LE}$ remain ambiguous due to varied eccentric programs and undefined optimal dosing [53].

5.1.3. Anti-Inflammatory Medications. Five recent placebocontrolled trials demonstrate that topical nonsteroidal antiinflammatory medications are effective within four weeks in the treatment of LE [54-58]. There have been no consensuses on the superiority of oral versus topical NSAIDs in pain control, though oral NSAIDs may cause gastrointestinal adverse effects [59]. Hay and colleagues reported that corticosteroid injection was superior than NSAIDs in improving patients' outcomes within four weeks, without longterm benefits at 12 months [43]. Other studies also found that despite of its short-term pain relief, corticosteroid injection is inferior than watchful waiting or physical therapy at one year follow-up $[60,61]$. Notably, repeated injections of the corticosteroid may result in iatrogenic tendon rupture and muscle atrophy. Therefore, clinicians should be alert to the abuse of corticosteroids in the treatment of LE on account of poor long-term efficacy and potential adverse effects [62].

5.1.4. Counterforce Braces. Counterforce bracing has been popular in the treatment of LE for decades. Using counterforce braces can significantly alleviate pain by pressing on the forearm extensor muscles and then inhibiting and dispersing the stress on the origin of affected ECRB, thereby facilitating its self-repair [29]. Biomechanical studies have shown that immobilizing the forearm with braces can significantly lessen the stress on the ECRB origin [63]. The latest randomized controlled double-blind trial shows that the use of counterforce brace can significantly decrease the frequency and severity of pain for 2-12 weeks and improve the elbow function at 26 weeks, compared with the placebo group [64]. In addition to counterforce braces, cock-up wrist braces during activities of daily living can limit wrist extension and firing of the ECRB tendon, allowing the injured tendon to heal [65].

5.1.5. Extracorporeal Shock-Wave Therapy. Extracorporeal shock-wave therapy (ESWT) is one of the commonly used physical therapy modalities for treating LE, in spite of conflicting results in the available literature. The mechanism of ESWT has not been completely clarified, possibly including direct stimulation of healing, neovascularization, direct suppressive effects on nociceptors, and a hyperstimulation mechanism blocking the gate control [66]. ESWT may not reverse the pathology of LE but improve the symptoms of LE. ESWT is not appropriate for acute LE but is recommended when symptoms persist for more than 6 months or when other conservative treatments fail [67].

5.1.6. Acupuncture. Acupuncture is a green, simple, inexpensive, and beneficial treatment for musculoskeletal diseases, especially for dysfunction and pain symptoms [68]. However, current data from evidence-based medicine indicate conflicting results. Two systematic reviews have not concluded whether acupuncture was effective for $\operatorname{LE}[69,70]$, whereas three systematic reviews suggest that acupuncture is very effective in relieving LE pain in the short term, with the long-term results remaining unclear [71-73].

5.1.7. Autologous Blood Injection (ABI). Local ABI has been proved effective and widely used for treatment of LE. There are two hypotheses for the mechanism of ABI. On the one hand, ABI works by initiating the inflammatory response around the affected tendon, which may result in cellular and humoral mediators to induce a healing cascade [74]. On the other hand, ABI allows delivery of growth factors inducing fibroblastic mitosis, triggering stem cells, and angiogenesis, probably promoting angiogenesis and collagen formation [75]. Current evidence suggests that ABI can achieve good outcome in the short term; however, no benefit has been found in the medium- or long-term follow-up [76, 77]. In addition, it should be noted that ABI has high risks of injection site pain and skin reaction. Accordingly, its indications should restrict to those recalcitrant cases when other modalities of treatment are less effective.

5.1.8. Platelet-Rich Plasma (PRP) Injection. PRP has gained popularity in recent years in the treatment for LE. The exact mechanisms of PRP remain unknown. There are theories attributed to platelets releasing high concentrations of platelet-derived growth factors enhancing wound healing, bone healing, and tendon healing [78]. However, available 
studies have reported conflicting results, which make it difficult to draw clear conclusions on PRP for LE. The latest systematic review manifested that PRP injection has no obvious effects on the treatment of chronic LE [79]. Several studies have shown that PRP does not provide significant benefits over corticosteroids, ABI, or even saline injections [80-82], whereas other studies reported better results with pain relief and function improvement $[83,84]$.

5.2. Operative Treatment. Surgical intervention can be an option for patients with persistent pain and disability that have failed appropriate nonoperative management.

The number of patients requiring surgical treatment is estimated about $4 \%$ to $11 \%$ [85]. There are mainly three surgical approaches, i.e., open, percutaneous, and arthroscopic techniques. The surgical focus is to debride the degenerated portion of the ECRB with or without repairing the ECRB tendon $[86,87]$. Evidence in the literature indicates fair to good results for these procedures, presenting surgeons with many options for treatment. However, there have been no definite understandings for the mechanism of good outcome.

5.2.1. Open Surgery. Open surgery involves a small lateral incision with dissection and degenerated tendon identification. After debridement of denatured tendon tissues, the main structure of the tendon can be repaired, lengthened, and fixed by drilling or decortication of the lateral epicondyle [88, 89]. Nirschl and Pettrone [90] reported 88 elbow surgical cases out of clinical series of 1,213 patients which involved excision and repair of the ECRB tendinosis tissue. The short-term outcomes of the original procedure were described as good to excellent by $85 \%$ of patients with an overall improvement rate of $98 \%$ and a return to full activity in $85 \%$ of patients [90]. In a recent retrospective study, Dunn et al. [91] presented 10- to 14-year follow-up results of the Nirschl surgical technique for $83 \mathrm{LE}$ patients with 92 elbows. Eighty-four percent of elbows were reported little or no pain, and $92 \%$ patients returned to normal elbow range of motion, while $93 \%$ of patients could return to their sports. The overall improvement rate was $97 \%$.

Coleman et al. [92] reported their 15 years of experience in treating refractory LE. Amongst 158 consecutive patients treated with open surgery, $94.6 \%$ achieved good or excellent results at an average follow-up of 9.8 years. Although the results of open surgery are positive, there is also a risk of instability of the elbow since excessive dissection of the LE may injure the lateral ligaments.

5.2.2. Percutaneous Surgery. Percutaneous surgical approach is mainly used for releasing the common extensor tendon origin at the lateral epicondyle. This technique has been demonstrated to be safe, reliable, and cost-effective $[93,94]$. Good midterm outcomes in pain relief have been widely reported with a percutaneous surgical approach [9596]. However, Pierce et al. [97] reported that arthroscopic and open techniques achieved a better prognosis than the percutaneous surgical approach for the treatment of LE.

In recent years, a novel technique termed as ultrasoundguided percutaneous tenotomy (UGPT) has been reported as a safe and effective procedure for the treatment of LE, with durable improvements in terms of symptoms, function, and ultrasound imaging at 1-year follow-up [98]. Barnes et al. [99] reported similar outcomes for 19 patients with chronic, refractory lateral, or medial elbow tendinopathy up to 1 year after the procedure. This novel procedure requires the assistance of the TX1 Tissue Removal System (Tenex Health, Lake Forest, CA), which is performed through an approximately $5 \mathrm{~mm}$ incision and uses ultrasonic energy to remove diseased tendon tissue in the damaged region, creating an acute inflammatory reaction and facilitating tendon healing [100].

Seng et al. [101] reported 20 patients with refractory LE treated with UGPT through TX1 Tissue Removal System. The results demonstrated that UGPT procedures could provide sustained pain relief and functional improvement for recalcitrant cases at 3-year follow-up.

Boden et al. [102] compared the effects of PRP and UGPT procedures in the treatment of medial and LE. No statistically significant difference was found between the two treatment modalities. They concluded that PRP and UGPT procedures were both effective in aspect of pain relief and the improvement of function and life quality.

5.2.3. Arthroscopic Surgery. Elbow arthroscopy has been used for the treatment of LE as well. It was first described by Baker and considered as a minimally invasive and efficient surgical procedure [103]. The major advantages of this procedure are quick return to work and the ability to treat the potential intra-articular pathology through visualization of the entire elbow joint. Baker et al. [103] reported that $87 \%$ of LE patients undergoing elbow arthroscopy had good longterm follow-up results. Various studies have shown a lower complication rate of arthroscopic treatment than that of open and percutaneous approach [104-106]. However, recent systematic review studies reported a compromise result, demonstrating no differences among open, arthroscopic, and percutaneous surgical techniques for LE regarding the duration of return to work, complication rate, or patient satisfaction [97, 106]. Although there are generally positive results, elbow arthroscopy is thought to have a demanding learning curve with potentially risks of damage to the radial nerve and the lateral ulnar collateral ligament [107-109].

\section{Conclusions}

LE is a common cause of pain and disability affecting patients aged between 35 and 55 years. Most cases have a selflimiting course of between 12 and 18 months. However, symptoms can be persistent and refractory, thus needing interventional measures. Nonoperative treatment remains the priority and mainstay for LE. Most cases can be well treated with multiple nonoperative treatments, with as high as $90 \%$ success rate. However, there is no evidence 
suggesting the superiority of nonoperative treatment options. When nonoperative treatment fails, three surgical interventions will be recommended for patients with lateral LE, including open, percutaneous, and arthroscopic approaches. Similarly, no conclusions on the effectiveness of surgical interventions can be reached mainly due to a lack of high-quality evidence and inconsistent outcome measures.

\section{Data Availability}

The updated article data in the literature used to support the findings of this study are from previously reported studies and datasets, which have been cited. The processed data are listed as Table 1 and Table 2.

\section{Conflicts of Interest}

The authors declare no conflicts of interest regarding the publication of this paper.

\section{Authors' Contributions}

Kun-Long Ma and Hai-Qiang Wang conceived the study together. The manuscript was written by Kun-Long Ma and revised by Hai-Qiang Wang.

\section{Acknowledgments}

This study was supported by Basic and Frontier Research Projects of Chongqing, China (Project number: Ycstc, 2017nc5), Chongqing Municipal Commission of Health and Family Planning (Project number: 2017MSXM081), and the National Natural Science Foundation of China (Grant number: 81572182).

\section{References}

[1] F. Runge, "Zur Genese und Behandlung des schreibe Kranfes," Bed Klin Worchenschr, vol. 10, pp. 245-248, 1873.

[2] N. Smidt and D. A. van der Windt, "Tennis elbow in primary care," BMJ, vol. 333, pp. 927-928, 2006.

[3] K. Kurppa, E. Viikari-Juntura, E. Kuosma, M. Huuskonen, and P. Kivi, "Incidence of tenosynovitis or peritendinitis and epicondylitis in a meatprocessing factory," Scandinavian Journal of Work, Environment \& Health, vol. 17, no. 1, pp. 32-37, 1991.

[4] B. Silverstein, E. Welp, N. Nelson, and J. Kalat, "Claims incidence of work-related disorders of the upper extremities: Washington state, 1987 through 1995," American Journal of Public Health, vol. 88, no. 12, pp. 1827-1833, 1998.

[5] L. Bisset, E. Beller, and G. Jull, "Mobilisation with movement and exercise, corticosteroid injection,or wait and see for tennis elbow: randomised trial," BMJ, vol. 333, no. 7575, pp. 939-941, 2006.

[6] D. Eygendaal, F. T. G. Rahussen, and R. L. Diercks, "Biomechanics of the elbow joint in tennis players and relation to pathology," British Journal of Sports Medicine, vol. 41, no. 11, pp. 820-823, 2007.

[7] H. S. Lee, H. Y. Park, and J. O. Yoon, "Musicians' medicine: musculoskeletal problems in string players," Clinics in Orthopedic Surgery, vol. 5, no. 3, pp. 155-160, 2013.
[8] S. A. Taylor and J. A. Hannafin, "Evaluation and management of elbow tendinopathy," Sports Health, vol. 4, no. 5, pp. 384-393, 2012.

[9] D. M. Walz, J. S. Newman, and G. P. Konin, "Epicondylitis: pathogenesis, imaging, and treatment," Radiographics, vol. 30, no. 1, pp. 167-184, 2010.

[10] R. P. Nirschl, "Tennis elbow," Orthopedic Clinics of North America, vol. 4, pp. 787-800, 1973.

[11] S. K. Bishai and K. D. Plancher, "The basic science of lateral epicondylosis: update for thebfuture," Techniques in Orthopaedics, vol. 21, no. 4, pp. 250-255, 2006.

[12] P. Kannus and L. Józsa, "Histopathological changes preceding spontaneous rupture of a tendon: a controlled study of 891 patients," The Journal of Bone \& Joint Surgery, vol. 73, no. 10, pp. 1507-1525, 1991.

[13] B. S. Kraushaar and R. P. Nirschl, "Tendinosis of the elbow (tennis elbow): clinical features and findings of histological, immunohistochemical, and electron microscopy studies," The Journal of Bone \& Joint Surgery, vol. 81, no. 2, pp. 259-278, 1999.

[14] R. P. Nirschl and G. J. Alvarado, "Tennis elbow tendinosis: pathoanatomy, nonsurgical and surgical management," in Repetitive Motion Disorders of the Upper Extremity, pp. 467-479, American Academy of Orthopaedic Surgeons, Rosemont, IL, USA, 1995.

[15] M. Kjaer, "Role of extracellular matrix in adaptation of tendon and skeletal muscle to mechanical loading," Physiological Reviews, vol. 84, no. 2, pp. 649-698, 2004.

[16] J. C. Patterson-Kane, D. L. Becker, and T. Rich, "The pathogenesis of tendon microdamage in athletes: the horse as a natural model for basic cellular research," Journal of Comparative Pathology, vol. 147, no. 2-3, pp. 227-247, 2012.

[17] P. Kannus, "Etiology and pathophysiology of chronic tendon disorders in sports," Scandinavian Journal of Medicine \& Science in Sports, vol. 7, pp. 78-85, 1997.

[18] P. Sharma and N. Maffulli, "Tendon injury and tendinopathy: healing and repair," The Journal of Bone and Joint Surgery-American, vol. 87, pp. 187-202, 2005.

[19] P. Kannus, "Structure of the tendon connective tissue," Scandinavian Journal of Medicine and Science in Sports, vol. 10, pp. 312-320, 2000.

[20] B. K. Coombes, L. Bisset, and B. Vicenzino, "A new integrative model of lateral epicondylalgia," British Journal of Sports Medicine, vol. 43, pp. 252-258, 2009.

[21] R. Boushel, H. Langberg, S. Green, D. Skovgaard, J. Bülow, and M. Kjaer, "Blood flow and oxygenation in peritendinous tissue and calf muscle during dynamic exercise in humans," The Journal of Physiology, vol. 524, pp. 305-313, 2000.

[22] B. O. Ljung, H. Alfredson, and S. Forsgren, "Neurokinin 1receptors and sensory neuropeptides in tendon insertions at the medial and lateral epicondyles of the humerus Studies on tennis elbow and medial epicondylalgia," Journal of Orthopaedic Research, vol. 22, pp. 321-327, 2004.

[23] Y. Uchio, M. Ochi, K. Ryoke, Y. Sakai, Y. Ito et al., "Expression of neuropeptides and cytokines at the extensor carpi radialis brevis muscle origin," Journal of Shoulder and Elbow Surgery, vol. 11, no. 6, pp. 570-575, 2002.

[24] S. H. Han, H. J. An, J. Y. Song et al., "Effects of corticosteroid on the expressions of neuropeptide and cytokine mRNA and on tenocyte viability in lateral epicondylitis," Journal of Inflammation, vol. 9, p. 40, 2012.

[25] S. H. Hsu, T. C. Moen, and W. N. Levine, "'Physical examination of the athlete's elbow," The American Journal of Sports Medicine, vol. 40, no. 3, pp. 699-708, 2012. 
[26] Z. Ahmad, N. Siddiqui, and S. S. Malik, "Lateral epicondylitis: a review of pathology and management," The Bone \& Joint Journal, vol. 95, no. 9, pp. 1158-1164, 2013.

[27] E. R. Dorf, A. B. Chhabra, S. R. Golish, J. L. McGinty, and M. E. Pannunzio, "Effect of elbow position on grip strength in the evaluation of lateral epicondylitis," The Journal of Hand Surgery, vol. 32, no. 6, pp. 882-886, 2007.

[28] F. Faro and J. M. Wolf, "Lateral epicondylitis: review and current concepts," The Journal of Hand Surgery, vol. 32, no. 8, pp. 1271-1279, 2007.

[29] R. P. Nirschl and E. S. Ashman, "Elbow tendinopathy: tennis elbow," Clinics in Sports Medicine, vol. 22, pp. 813-836, 2003.

[30] A. Vaquero-Picado, R. Barco, and S. A. Antuña, "Lateral epicondylitis of the elbow," EFORT Open Reviews, vol. 1, no. 11, pp. 391-397, 2017.

[31] S. D. McCallum, J. A. Paoloni, and G. A. Murrell, "Five-year prospective comparison study of topical glyceryl trinitrate treatment of chronic lateral epicondylosis at the elbow," British Journal of Sports Medicine, vol. 45, pp. 416-420, 2011.

[32] R. C. Gardner, "Tennis elbow: diagnosis, pathology and treatment: nine severe cases treated by a new reconstructive operation," Clinical Orthopaedics and Related Research, vol. 72, pp. 248-253, 1970.

[33] E. L. Zwerus, M. P. Somford, F. Maissan et al., "Physical examination of the elbow, what is the evidence? A systematic literature review," British Journal of Sports Medicine, vol. 52, no. 19, pp. 1253-1260, 2018.

[34] K. Sasaki, M. Tamakawa, K. Onda et al., "The detection of the capsular tear at the undersurface of the extensor carpi radialis brevis tendon in chronic tennis elbow: the value of magnetic resonance imaging and computed tomography arthrography," Journal of Shoulder and Elbow Surgery, vol. 20, no. 3, pp. 420-425, 2011.

[35] V. C. Dones, K. Grimmer, K. Thoirs, C. G. Suarez, and J. Luker, "The diagnostic validity of musculoskeletal ultrasound in lateral epicondylalgia: a systematic review," BMC Medical Imaging, vol. 14, no. 1, p. 10, 2014.

[36] D. Connell, F. Burke, P. Coombes et al., "Sonographic examination of lateral epicondylitis," American Journal of Roentgenology, vol. 176, no. 3, pp. 777-782, 2001.

[37] C. Du Toit, M. Stieler, R. Saunders, and B. Vicenzino, "Diagnostic accuracy of power Doppler ultrasound in patients with chronic tennis elbow," British Journal of Sports Medicine, vol. 42, no. 11, pp. 872-876, 2008.

[38] M. Aoki, T. Wada, S. Isogai, K. Kanaya, H. Aiki, and T. Yamashita, "Magnetic resonance imaging findings of refractory tennis elbows and their relationship to surgical treatment," Journal of Shoulder and Elbow Surgery, vol. 14, no. 2, pp. 172-177, 2005.

[39] D. Mackay, A. Rangan, G. Hide et al., "The objective diagnosis of early tennis elbow by magnetic resonance imaging," Occupational Medicine, vol. 53, no. 5, pp. 309-312, 2003.

[40] T. T. Miller, M. A. Shapiro, E. Schultz, and P. E. Kalish, "Comparison of sonography and MRI for diagnosing epicondylitis," Journal of Clinical Ultrasound, vol. 30, pp. 193202, 2002.

[41] A. Savnik, B. Jensen, J. Nørregaard et al., "Magnetic resonance imaging in the evaluation of treat.ment response of lateral epicondylitis of the elbow," European Radiology, vol. 14, no. 6, pp. 964-969, 2004.

[42] P. Hoogvliet, M. S. Randsdorp, R. Dingemanse, B. W. Koes, and B. Huisstede, "Does effectiveness of exercise therapy and mobilisation techniques offer guidance for the treatment of lateral and medial epicondylitis? A systematic review,"
British Journal of Sports Medicine, vol. 47, pp. 1112-1119, 2013.

[43] E. M. Hay, S. M. Paterson, M. Lewis et al., "Pragmatic randomised controlled trial of local corticosteroid injection and naproxen for treatment of lateral epicondylitis of elbow in primary care," BMJ, vol. 319, no. 7215, pp. 964-968, 1999.

[44] L. M. Bisset and B. Vicenzino, "Physiotherapy management of lateral epicondylalgia," Journal of Physiotherapy, vol. 61, no. 4, pp. 174-181, 2015.

[45] B. K. Coombes, L. Bisset, and B. Vicenzino, "Management of lateral elbow tendinopathy: one size does not fit all," Journal of Orthopaedic \& Sports Physical Therapy, vol. 45, no. 11, pp. 938-949, 2015.

[46] S. E. G. Sims, K. Miller, J. C. Elfar et al., "Non-surgical treatment of lateral epicondylitis: a systematic review of randomized controlled trials," HAND, vol. 9, no. 4, pp. 419-446, 2014.

[47] R. Dingemanse, M. Randsdorp, B. W. Koes, and B. M. A. Huisstede, "Evidence for the effectiveness of electrophysical modalities for treatment of medial and lateral epicondylitis: a systematic review," British Journal of Sports Medicine, vol. 48, no. 12, pp. 957-965, 2014.

[48] C. Weber, V. Thai, K. Neuheuser, K. Groover, and O. Christ, "Efficacy of physical therapy for the treatment of lateral epicondylitis: a meta-analysis," BMC Musculoskeletal Disorders, vol. 16, no. 1, p. 223, 2015.

[49] T. L. Sevier and C. W. Stegink-Jansen, "Astym treatment vs. eccentric exercise for lateral elbow tendinopathy: a randomized controlled clinical trial," PeerJ, vol. 3, p. e967, 2015.

[50] A. Selvanetti, A. Barrucci, A. Antonaci et al., "L'esercisio eccentrico mella rieducazione funzionale dell'epicondilite," Medicina Dello Sport; Rivista di Fisiopatologia Dello Sport, vol. 56, pp. 103-113, 2003.

[51] J. Söderberg, W. J. Grooten, and B. O. Äng, "Effects of eccentric training on hand strength in subjects with lateral epicondylalgia: a randomized-controlled trial," Scandinavian Journal of Medicine \& Science in Sports, vol. 22, no. 6, pp. 797-803, 2012.

[52] T. F. Tyler, G. C. Thomas, S. J. Nicholas, and M. P. McHugh, "Addition of isolated wrist extensor eccentric exercise to standard treatment for chronic lateral epicondylosis: a prospective randomized trial," Journal of Shoulder and Elbow Surgery, vol. 19, no. 6, pp. 917-922, 2010.

[53] J. Raman, J. C. MacDermid, and R. Grewal, "Effectiveness of different methods of resistance exercises in lateral epicondylosis-a systematic review," Journal of Hand Therapy, vol. 25, no. 1, pp. 5-26, 2012.

[54] R. Burnham, R. Gregg, P. Healy, and R. Steadward, "The effectiveness of topical diclofenac for lateral epicondylitis," Clinical Journal of Sport Medicine, vol. 8, no. 2, pp. 78-81, 1998.

[55] P. J. Jenoure, A. Rostan, G. Gremion et al., "Multicentre, double-blind, controlled clinical study on the efficacy of diclofenac epolamine Tissugel plaster in patients with epicondylitis," Medicina Dello Sport, vol. 50, no. 3, pp. 285-292, 1997.

[56] D. Schapira, S. Linn, and Y. Scharf, "A placebo-controlled evaluation of diclofenac diethylamine salt in the treatment of lateral epicondylitis of the elbow," Current Therapeutic Research, vol. 49, no. 2, pp. 162-168, 1991.

[57] G. Spacca, A. Cacchio, A. Forgacs et al., "Analgesic efficacy of a lecithin- vehiculated diclofenac epolamine gel in shoulder periarthritis and lateral epicondylitis: a placebo-controlled, multicenter, randomized, double-blind clinical trial," Drugs 
Under Experimental and Clinical Research, vol. 31, no. 4, pp. 147-154, 2005.

[58] N. Tsuyama, K. Nichikawa, M. Tsujimoto, Y. Miyanaga, H. Mizushima, and A. Nakajima, "Clinical evaluation of nonsteroidal anti-inflammation/analgesics for external use Indomethacin ointment in the orthopaedic field," Clinical Evaluation, vol. 7, pp. 285-309, 1979.

[59] P. Pattanittum, T. turner, S. green, and R. Buchbinder, "Nonsteroidal antiinflammatory drugs (NSAIDs) for treating lateral elbow pain in adults," Cochrane Database of Systematic Reviews, vol. 5, Article ID CD003686, 2013.

[60] G. Johnson, K. Cadwallader, S. Scheffel, and T. D. Epperly, "Treatment of lateral epicondylitis," American Family Physician, vol. 76, no. 6, pp. 843-848, 2007.

[61] Z. Foster, T. Voss, J. Hatch et al., "Corticosteroid injections for common musculoskeletal conditions," AAFP Journal, vol. 92, no. 8, pp. 694-699, 2015.

[62] B. K. Coombes, L. Bisset, P. Brooks, A. Khan, and B. Vicenzino, "Effect of corticosteroid injection, physiotherapy, or both on clinical outcomes in patients with unilateral lateral epicondylalgia: a randomized controlled trial," JAMA, vol. 309, no. 5, pp. 461-469, 2013.

[63] M. Walther, S. Kirschner, A. Koenig, T. Barthel, and F. Gohlke, "Biomechanical evaluation of braces used for the treatment of epicondylitis," Journal of Shoulder and Elbow Surgery, vol. 11, no. 3, pp. 265-270, 2002.

[64] M. Kroslak, K. Pirapakaran, and G. A. C. Murrell, "Counterforce bracing of lateral epicondylitis: a prospective, randomized, double-blinded, placebo-controlled clinical trial," Journal of Shoulder and Elbow Surgery, vol. 28, no. 2, pp. 288-295, 2019.

[65] Y. Kobayashi, K. Suzuki, K. Ito, and Y. Nagata, "The effect of dorsal cock-up splint for the epicondylitis lateralis of the elbow (Tennis elbow)," Orthopedics \& Traumatology, vol. 31, no. 4, pp. 747-749, 1983.

[66] A. Notarnicola and B. Moretti, "The biological effects of extracorporeal shock wave therapy (eswt) on tendon tissue," Muscles, Ligaments and Tendons Journal, vol. 2, no. 1, p. 33, 2012.

[67] D. Stasinopoulos, "Can extracorporeal shock-wave therapy be used for the management of lateral elbow tendinopathy," World Journal of Methodology, vol. 8, no. 3, 2018.

[68] NIH, “Acupuncture," NIH Consensus Statement, vol. 15, no. 5, pp. 1-34, 1997.

[69] H. Tang, H. Fan, J. Chen et al., "Acupuncture for lateral epicondylitis: a systematic review," Evidence-Based Complementary and Alternative Medicine, vol. 2015, Article ID 861849, 13 pages, 2015.

[70] A. P. R. Buchbinder, S. E. Green, and P. A. A. Struijs, “Tennis elbow," BMJ Clinical Evidence, vol. 2008, p. 1117, 2008.

[71] K. V. Trinh, S. D. Phillips, E. Ho et al., "Acupuncture for the alleviation of lateral epicondyle pain: a systematic review," Rheumatology, vol. 43, no. 9, pp. 1085-1090, 2004.

[72] L. Bisset, A. Paungmali, B. Vicenzino et al., "A systematic review and meta-analysis of clinical trials on physical interventions for lateral epicondylalgia," British Journal of Sports Medicine, vol. 39, no. 7, pp. 411-422, 2005.

[73] M. Gadau, W. F. Yeung, H. Liu et al., "Acupuncture and moxibustion for lateral elbow pain: a systematic review of randomized controlled trials," BMC Complementary and Alternative Medicine, vol. 14, no. 1, p. 136, 2014.

[74] S. G. Edwards and J. H. Calandruccio, "Autologous blood injections for refractory lateral epicondylitis," The Journal of Hand Surgery, vol. 28, no. 2, pp. 272-278, 2003.
[75] L. Creaney, A. Wallace, M. Curtis, and D. Connell, "Growth factor-based therapies provide additional benefit beyond physical therapy in resistant elbow tendinopathy: a prospective, single-blind, randomised trial of autologous blood injections versus platelet-rich plasma injections," British Journal of Sports Medicine, vol. 45, no. 12, pp. 966-971, 2011.

[76] F. Sirico, F. Ricca, F. di Meglio et al., "Local corticosteroid versus autologous blood injections in lateral epicondylitis: meta-analysis of randomized controlled trials," European Journal of Physical and Rehabilitation Medicine, vol. 53, no. 3, pp. 483-491, 2017.

[77] X. Qian, Q. Lin, K. Wei, B. Hu, P. Jing, and J. Wang, "Efficacy and safety of autologous blood products compared with corticosteroid injections in the treatment of lateral epicondylitis: a meta-analysis of randomized controlled trials," PMঊR, vol. 8, no. 8, pp. 780-791, 2016.

[78] S. Sampson, M. Gerhardt, and B. Mandelbaum, "Platelet rich plasma injection grafts for musculoskeletal injuries: a review," Current Reviews in Musculoskeletal Medicine, vol. 1, no. 3-4, pp. 165-174, 2008.

[79] R. J. De Vos, J. Windt, and A. Weir, "Strong evidence against platelet-rich plasma injections for chronic lateral epicondylar tendinopathy: a systematic review," British Journal of Sports Medicine, vol. 48, no. 12, pp. 952-956, 2014.

[80] E. P. Palacio, R. R. Schiavetti, M. Kanematsu et al., "Effects of platelet-rich plasma on lateral epicondylitis of the elbow: prospective randomized controlled trial," Revista Brasileira de Ortopedia, vol. 51, no. 1, pp. 90-95, 2016.

[81] B. Montalvan, P. Le Goux, S. Klouche, D. Borgel, P. Hardy, and M. Breban, "Inefficacy of ultrasound-guided local injections of autologous conditioned plasma for recent epicondylitis: results of a double-blind placebo-controlled randomized clinical trial with one-year follow-up," Rheumatology, vol. 55, no. 2, pp. 279-285, 2015.

[82] R. D. Ford, W. P. Schmitt, K. Lineberry, and P. Luce, "A retrospective comparison of the management of recalcitrant lateral elbow tendinosis: platelet-rich plasma injections versus surgery," HAND, vol. 10, no. 2, pp. 285-291, 2015.

[83] A. K. Mishra, N. V. Skrepnik, S. G. Edwards et al., "Efficacy of platelet-rich plasma for chronic tennis elbow: a double-blind, prospective, multicenter, randomized controlled trial of 230 patients," The American Journal of Sports Medicine, vol. 42, no. 2, pp. 463-471, 2014.

[84] C. Thanasas, G. Papadimitriou, C. Charalambidis, L. Paraskevopoulos, and A. Papanikolaou, "Platelet-rich plasma versus autologous whole blood for the treatment of chronic lateral elbow epicondylitis: a randomized controlled clinical trial," The American Journal of Sports Medicine, vol. 39, no. 10, pp. 2130-2134, 2011.

[85] B. Kniesel, J. Huth, G. Bauer, and F. Mauch, "Systematic diagnosis and therapy of lateral elbow pain with emphasis on elbow instability," Archives of Orthopaedic and Trauma Surgery, vol. 134, no. 12, pp. 1641-1647, 2014.

[86] R. P. Calfee, A. Patel, M. F. DaSilva, and E. Akelman, "Management of lateral epicondylitis: current concepts," Journal of the American Academy of Orthopaedic Surgeons, vol. 16, no. 1, pp. 19-29, 2008.

[87] A. Wilhelm, "Lateral epicondylitis review and current concepts," The Journal of Hand Surgery, vol. 34, no. 7, pp. 1358-1359, 2009.

[88] V. S. Kumar, A. A. Shetty, K. J. Ravikumar, and M. J. F. Fordyce, "Tennis elbow-outcome following the Garden procedure: a retrospective study," Journal of Orthopaedic Surgery, vol. 12, no. 2, pp. 226-229, 2004. 
[89] M. S. Cohen, A. A. Romeo, S. P. Hennigan, and M. Gordon, "Lateral epicondylitis: anatomic relationships of the extensor tendon origins and implications for arthroscopic treatment," Journal of Shoulder and Elbow Surgery, vol. 17, no. 6, pp. 954-960, 2008.

[90] R. P. Nirschl and F. A. Pettrone, "Tennis elbow the surgical treatment of lateral epicondylitis," The Journal of Bone and Joint surgery, vol. 61, no. 6A, pp. 832-839, 1979.

[91] J. H. Dunn, J. J. Kim, L. Davis, and R. P. Nirschl, "Ten-to 14year follow-up of the Nirschl surgical technique for lateral epicondylitis," The American Journal of Sports Medicine, vol. 36, no. 2, pp. 261-266, 2008.

[92] B. Coleman, J. F. Quinlan, and J. A. Matheson, "Surgical treatment for lateral epicondylitis: a long-term follow-up of results," Journal of Shoulder and Elbow Surgery, vol. 19, no. 3, pp. 363-367, 2010.

[93] A. B. Grundberg and J. F. Dobson, "Percutaneous release of the common extensor origin for tennis elbow," Clinical Orthopaedics and Related Research, vol. 376, no. 376, pp. 137-140, 2000.

[94] T. Kaleli, C. Ozturk, A. Temiz et al., "Surgical treatment of tennis elbow: percutaneous release of the common extensor origin," Acta Orthopaedica Belgica, vol. 70, no. 2, pp. 131133, 2004.

[95] B. K. Cho, Y. M. Kim, D. S. Kim et al., "Mini-open muscle resection procedure under local anesthesia for lateral and medial epicondylitis," Clinics in Orthopedic Surgery, vol. 1, no. 3, pp. 123-127, 2009.

[96] M. A. Nazar, S. Lipscombe, S. Morapudi et al., "Percutaneous tennis elbow release under local anaesthesia," The Open Orthopaedics Journal, vol. 6, no. 1, pp. 129-132, 2012.

[97] T. P. Pierce, K. Issa, B. T. Gilbert et al., "A systematic review of tennis elbow surgery: open versus arthroscopic versus percutaneous release of the common extensor origin," Arthroscopy: The Journal of Arthroscopic \& Related Surgery, vol. 33, no. 6, pp. 1260-1268.e2, 2017.

[98] J. S. Koh, P. C. Mohan, T. S. Howe et al., "Fasciotomy and surgical tenotomy for recalcitrant lateral elbow tendinopathy," The American Journal of Sports Medicine, vol. 41, no. 3, pp. 636-644, 2013.

[99] D. E. Barnes, J. Beckley, and J. Smith, "Percutaneous ultrasonic tenotomy for chronic elbow tendinosis: a prospective study," Journal of Shoulder and Elbow Surgery, vol. 24 , no. 1, pp. 67-73, 2015.

[100] J. A. Jacobson, S. M. Kim, and M. K. Brigido, "Ultrasoundguided percutaneous tenotomy," Seminars in Musculoskeletal Radiology, vol. 20, no. 5, pp. 414-421, 2016.

[101] C. Seng, P. C. Mohan, S. B. J. Koh et al., "Ultrasonic percutaneous tenotomy for recalcitrant lateral elbow tendinopathy," The American Journal of Sports Medicine, vol. 44, no. 2, pp. 504-510, 2015.

[102] A. L. Boden, M. T. Scott, P. P. Dalwadi et al., "Platelet-rich plasma versus Tenex in the treatment of medial and lateral epicondylitis," Journal of Shoulder \& Elbow Surgery, vol. 28, no. 1, pp. 112-119, 2019

[103] C. L. Baker Jr. and C. L. Baker, "Long-term follow-up of arthroscopic treatment of lateral epicondylitis," The American Journal of Sports Medicine, vol. 36, no. 2, pp. 254-260, 2008.

[104] S. Karkhanis, A. Frost, and N. Maffulli, "Operative management of tennis elbow: a quantitative review," British Medical Bulletin, vol. 88, no. 1, pp. 171-188, 2008.
[105] M. L. Pomerantz, "Complications of lateral epicondylar release," Orthopedic Clinics of North America, vol. 47, no. 2, pp. 445-469, 2016.

[106] M. B. Burn, R. J. Mitchell, S. R. Liberman, D. M. Lintner, J. D. Harris, and P. C. McCulloch, "Open, arthroscopic, and percutaneous surgical treatment of lateral epicondylitis: a systematic review," HAND, vol. 13, no. 3, pp. 264-274, 2018.

[107] R. Tosti, J. Jennings, and J. M. Sewards, "Lateral epicondylitis of the elbow," The American Journal of Medicine, vol. 126, no. 4, pp. 357.e1-357.e6, 2013.

[108] F. Savoie, W. VanSice, and M. O’Brien, "Arthroscopic tennis elbow release," Journal of Shoulder and Elbow Surgery, vol. 19, no. 2, pp. 31-36, 2010.

[109] A. M. Othman, “Arthroscopic versus percutaneous release of common extensor origin for treatment of chronic tennis elbow," Archives of Orthopaedic and Trauma Surgery, vol. 131, no. 3, pp. 383-388, 2011. 